\title{
miR-146a Influences Energy Metabolism, Cell Differentiation and Innate Immunity
}

\author{
Jessica M Huszar and Christopher J Payne*
}

Departments of Pediatrics and OB/GYN, Northwestern University Feinberg School of Medicine, Human Molecular Genetics Program, Ann \& Robert H. Lurie Children's Hospital of Chicago Research Center, Chicago, Illinois 60611, USA

\begin{abstract}
MicroRNAs play key regulatory roles in many different biological processes, including development, differentiation, homeostasis and inflammation. The latest version of miRBase lists over 1100 distinct microRNA sequences in mice and over 1800 in humans. One pair of mature microRNAs whose 3' regions differ by only 2 nucleotides, miR-146a and miR$146 b$, is involved in metabolism, differentiation and immunity. NF-KB directly induces miR-146a, while both miR-146a and miR-146b target NF-KB pathway components interleukin-1 receptor-associated kinase 1 (Irak1) and tumor necrosis factor receptor-associated factor-6 (Traf6) for repression. Inhibition of miR-146a increases glucose-stimulated insulin secretion and promotes differentiation of mouse spermatogonia. Muscle-specific inactivation of mediator complex subunit 1 (Med1), another miR-146a target, enhances insulin sensitivity and improves glucose tolerance in mice. This review highlights the role of miR-146a in metabolic regulation, hematopoietic and spermatogenic differentiation, and induction of the immune response.
\end{abstract}

Keywords: $m i R-146 a$; Glucose metabolism; Spermatogonial differentiation; Immune response

\section{Introduction}

In mice, the miR-146a gene locus encodes a 65 -nucleotide (nt) stem loop structure that forms the precursor miR-146a molecule. This sequence is 99 -nt in humans. miR-146b, meanwhile encodes a 109-nt stem loop structure in mice and a 73-nt sequence in humans. Enzymatic processing by Dicer yields 22 -nt mature $m i R-146 a$ and $m i R$ $146 b$ in both species. While the mature forms of $m i R-146 a$ and $m i R-$ $146 b$ differ by only 2 nucleotides, the two genes are located on different chromosomes and have distinct mechanisms of regulation. Initial observations of $m i R-146 a$ were an induction in gene activity following the exposure of human monocytic cells to lipopolysaccharides (LPS), a model for activating the innate immune response [1]. LPS exposure activates Toll-like receptors, which in turn leads to the recruitment and association of IRAK1 and TRAF6, members of the NF- $\kappa B$ pathway. NF- $\kappa B$ binds to and upregulates $m i R-146 a$, which then targets and represses both Irak1 and Traf6 mRNAs to modulate the immune response [1]. miR-146b also targets Irakl and Traf6 mRNAs in the NF$\kappa \mathrm{B}$ pathway [1].

Meanwhile, during the differentiation of hematopoietic progenitor cells to megakaryocytes, $m i R-146 a$ is transcriptionally repressed by promyelocytic leukemia zinc finger (PLZF; ZBTB16) [2]. Downregulation of $m i R-146 a$ permits the expression of chemokine (C-X-C motif) receptor 4 (CXCR4), a target of $m i R-146 a$ and an essential protein for megakaryopoiesis [2]. miR-146a downregulation also occurs during spermatogonial differentiation, when undifferentiated male germ cells commit to the spermatogenic process [3]. When $m i R$ $146 a$ is overexpressed in hematopoietic stem cells, which are then transplanted into recipient bone marrow, decreased erythropoiesis and impaired lymphopoiesis result [4]. Indeed, $m i R-146 a$ overexpression promotes myeloid differentiation and macrophage development at the expense of other cell lineages [5].

Studies with the insulin-secreting cell line MIN6B1 show that, in addition to innate immunity and cell differentiation, $m i R-146 a$ functions to modulate glucose metabolism [6]. Inhibition of $m i R-146 a$ in IL-1 $\beta$-treated cells increases glucose-stimulated insulin secretion and provides protection against cytokine-induced apoptosis [6]. When Med1, a miR-146a target gene, is genetically ablated in the muscle cells of mice, these animals exhibit significantly lower glucose levels than control animals when administered a glucose tolerance test [7]. Likewise, the Med1 tissue-specific knockout mice show a greater hypoglycemic response to exogenous insulin than control mice when given an insulin tolerance test [7]. These findings reveal a role for $\mathrm{miR}$ $146 a$ in regulating metabolic processes within cells and tissues.

\section{Promoter of $m i R-146 a$}

The miR-146a gene, located on chromosome 11 in mouse and chromosome 5 in human, contains its own promoter with validated NF- $\kappa \mathrm{B}$ and PLZF binding sites [1,2]. Many additional transcription factors are likely to bind sequences within the $m i R-146 a$ promoter. Indeed, in silico analysis using MatInspector (Genomatix Software $\mathrm{GmbH}$ ) predicts 824 putative binding sites between the transcription start site of primary $m i R-146 a$ and $2 \mathrm{~kb}$ upstream, including those for retinoic acid receptors (RAR $\alpha, \mathrm{RAR} \beta, \mathrm{RXR}$ ) and DMRT1 (doublesex and mab-3 related transcription factor 1) (unpublished observations, Huszar and Payne). Table 1 lists selected transcription factors predicted to bind to the $m i R-146 a$ promoter. It is clear that both NF- $\mathrm{kB}$ and PLZF modulate $m i R-146 a$ through these promoter sequences, resulting in the

\begin{tabular}{|c|c|c|}
\hline C/EBP $\alpha$ & PLZF & RAR $\gamma$ \\
\hline ETS1 & PU.1 & RXR \\
\hline NF-אB & RAR $\alpha$ & DMRT1 \\
\hline
\end{tabular}

Table 1: Selected transcription factors predicted to bind to the miR-146a promoter

*Corresponding author: Christopher J Payne, Ann \& Robert H. Lurie Children's Hospital of Chicago Research Center, Chicago, IL 60611 USA, Tel: +1 773755 6316; Fax: +1 773755 6593; E-mail: c-payne@northwestern.edu

Received June 26, 2013; Accepted July 27, 2013; Published August 03, 2013

Citation: Huszar JM, Payne CJ (2013) miR-146a Influences Energy Metabolism, Cell Differentiation and Innate Immunity. Metabolomics 3: 119. doi:10.4172/21530769.1000119

Copyright: (c) 2013 Huszar JM, et al. This is an open-access article distributed under the terms of the Creative Commons Attribution License, which permits unrestricted use, distribution, and reproduction in any medium, provided the original author and source are credited. 
differential expression of this microRNA and its subsequent influence on energy metabolism, cell differentiation and innate immunity.

Like $m i R-146 a$, the $m i R-146 b$ gene has its own promoter, which is activated by interleukin (IL)- $1 \beta$ in alveolar epithelial cells and by $\gamma$-interferon (IFN- $\gamma$ ) in retinal pigment epithelial cells [8,9]. $m i R-146 b$ is located on chromosome 19 in mouse and chromosome 10 in human. The human MIR146B promoter contains a putative signal transducer and activator of transcription 1 (STAT1) binding sequence, although a functional demonstration of STAT1 binding to the MIR146B promoter has not yet been shown [9]. Overall, the regulation of $m i R-146 b$ has not been extensively characterized relative to $m i R-146 a$, and much additional work remains to enable a more accurate and complete comparison between the expression of miR-146b and miR-146a.

Recently, CpG methylation levels and histone modifications in the miR-146a promoter were assessed in 11 cell lines, some of which expressed latent membrane protein 1 (LMP1), a known inducer of $m i R-146 a[10,11]$. In cells in which $m i R-146 a$ was silent, CpG islands were heavily methylated in two cell lines and moderately methylated in two others. Conversely, in cells actively expressing $m i R$ $146 a, \mathrm{CpG}$ dinucleotides were completely unmethylated [11]. Silent hypermethylated miR-146a promoters were also lacking acetylated histones $\mathrm{H} 3$ and $\mathrm{H} 4$, and $\mathrm{H} 3 \mathrm{~K} 4 \mathrm{me} 2$, a mark of active chromatin [11]. In contrast, active $m i R-146 a$ associated with $\mathrm{H} 3 \mathrm{~K} 4 \mathrm{me} 2$ and moderate levels of acetylated $\mathrm{H} 3$ and $\mathrm{H} 4$. Thus, CpG methylation levels and euchromatic histone modification marks influence the activity of the $m i R-146 a$ promoter, as they do with the promoters of protein coding genes.

\section{Role of $m i R-146 a$ in energy metabolism}

The release of insulin from the $\beta$-cells of the pancreas is a key step to ensure optimal, steady state levels of glucose in the blood. Susceptibility of these cells to pro-inflammatory cytokines like IL- $1 \beta$, tumor necrosis factor (TNF)- $\alpha$ and IFN- $\gamma$ is a major concern, as prolonged exposure can result in cellular damage and death. When MIN6B1 cells are incubated with IL- $1 \beta$, TNF- $\alpha$ and IFN $-\gamma, m i R-146 a$ is significantly upregulated in an NF- $\kappa \mathrm{B}$-dependent manner [6]. IL-1 $\beta$-treated cells in which $m i R-146 a$ activity is blocked exhibit increased insulin secretion and reduced cytokine-induced cell death [6]. Meanwhile, in obese patients $m i R-146 b$ is downregulated in circulating monocytes [12]. Globular adiponectin concentrations regulate $m i R-146 b$ activity, which in turn inhibits NF- $\kappa \mathrm{B}$-mediated inflammation. However, $m i R-146 b$ is not directly involved in insulin signaling; it instead facilitates the antiinflammatory action of elevated globular adiponectin levels [12].

One individual miR-146a target mRNA validated by luciferase assays is Med1 [3]. Direct binding occurs between $m i R-146 a$ and the 3' untranslated region of Med1 [3]. When muscle-specific Med 1 knockout mice are generated and subjected to glucose tolerance tests, the mice show reduced glucose levels when compared to controls [7]. These conditional knockout mice also exhibit an increased hypoglycemic response to exogenous insulin. Taken together, these findings reveal that, on the one hand, high levels of miR-146a expression in insulin secreting cells adversely affect insulin release and cell survival, while on the other hand, depletion of miR-146a target genes like Med1 results in enhanced insulin sensitivity, improved glucose tolerance, and resistance to high-fat diet-induced obesity [7].

\section{Role of $m i R-146 a$ in cell differentiation}

We recently observed that $m i R-146 a$ is significantly downregulated $(\sim 180$-fold) when undifferentiated male germ cells commit to differentiate in mice [3]. This differentiation process involves the downregulation of stem cell-associated factors like PLZF, and the upregulation of factors like the Kit receptor (KIT) and stimulated by retinoic acid gene 8 (STRA8). Interestingly, Labbaye et al. [2] demonstrated PLZF binding in the miR-146a promoter to repress its activity in differentiating megakaryocytes. As PLZF activates as well as represses target genes, it is possible that PLZF might bind to $m i R-146 a$ in undifferentiated spermatogonia to promote its transcription, and that upon cell differentiation $m i R-146 a$ undergoes downregulation in a PLZF-dependent manner.

In hematopoietic stem cells, the ectopic overexpression of $m i R-146 a$ specifically and selectively promotes the development of monocytes that can mature into macrophages [5]. This occurs at the expense of other hematopoietic cell lineages. When $m i R-146 a$ is overexpressed in megakaryocytes, the ensuing growth, differentiation and maturation of megakaryocytes are impaired [2]. CXCR4 is repressed in these cells when $m i R-146 a$ is overexpressed. Similar results occur when PLZF is silenced. These results collectively show how $m i R-146 a$ influences specific cell fate decisions and lineage specification.

During transforming growth factor beta (TGF $\beta$ )-induced intestinal crypt cell differentiation, $m i R-146 b$ is upregulated and targets seven in absentia homolog 2 (SIAH2), an E3 ubiquitin ligase [13]. This repression of SIAH2 results in the expression of SMAD7, which binds to the TGF $\beta$ receptor and inhibits its phosphorylation of SMAD2 and SMAD3 $[13,14]$. The roles of $m i R-146 b$ in cell division and cancer, however, are conflicting. While upregulated $m i R-146 \mathrm{~b}$ can inhibit the metastasis of gliomas and breast cancer, $m i R-146 b$ overexpression has been detected in acute lymphoblastic leukemia, papillary thyroid carcinoma and lung tumors [15-19]. Further analysis is required to more accurately discern the functional roles of $m i R-146 b$ in cell proliferation, differentiation and transformation.

\section{Role of $m i R-146 a$ in innate immunity}

Macrophages, monocytes, natural killer cells and granulocytes, which comprise the innate immune system, serve as the initial line of defense against invading pathogens in an organism. Both the regulation of TNF- $\alpha$ transduction and the establishment of endotoxin tolerance in monocytes are influenced by $m i R-146 a[20,21]$. This microRNA also appears to function as a negative feedback regulator of inflammatory signaling in endothelial cells [22].

Taganov et al. [1] showed that human monocytic THP-1 cells exposed to LPS activated Toll-like receptor 4 (TLR-4) and induced both $m i R-146 a$ and $m i R-146 b$ as a response. Additional studies have demonstrated that miR-146a induction through activated TLR-2, -4 , or -5 is a general response in myeloid cells by bacteria or fungi or by exposure to IL- $1 \beta$ or TNF- $\alpha[23,24]$. These pro-inflammatory cytokines, for example, induce miR-146a expression in rheumatoid arthritis synovial tissue [25]. Thus, $m i R-146 a$ is activated by TLR family members and NF- $\mathrm{BB}$, whereby it functions to regulate Irak1, Traf6 and N $f k b$ in order to modulate the immune response to invading pathogens. The regulatory mechanisms involving $m i R-146 b$ and innate immunity are less well understood.

\section{Summary}

Like most microRNAs and other non-coding RNA molecules, $m i R$ $146 a$ regulates many distinct biological processes in different types of cells (Figure 1). Harboring its own promoter, miR-146a expression is regulated by transcription factor binding, $\mathrm{CpG}$ methylation and histone modification. miR-146a influences such distinct cellular events 

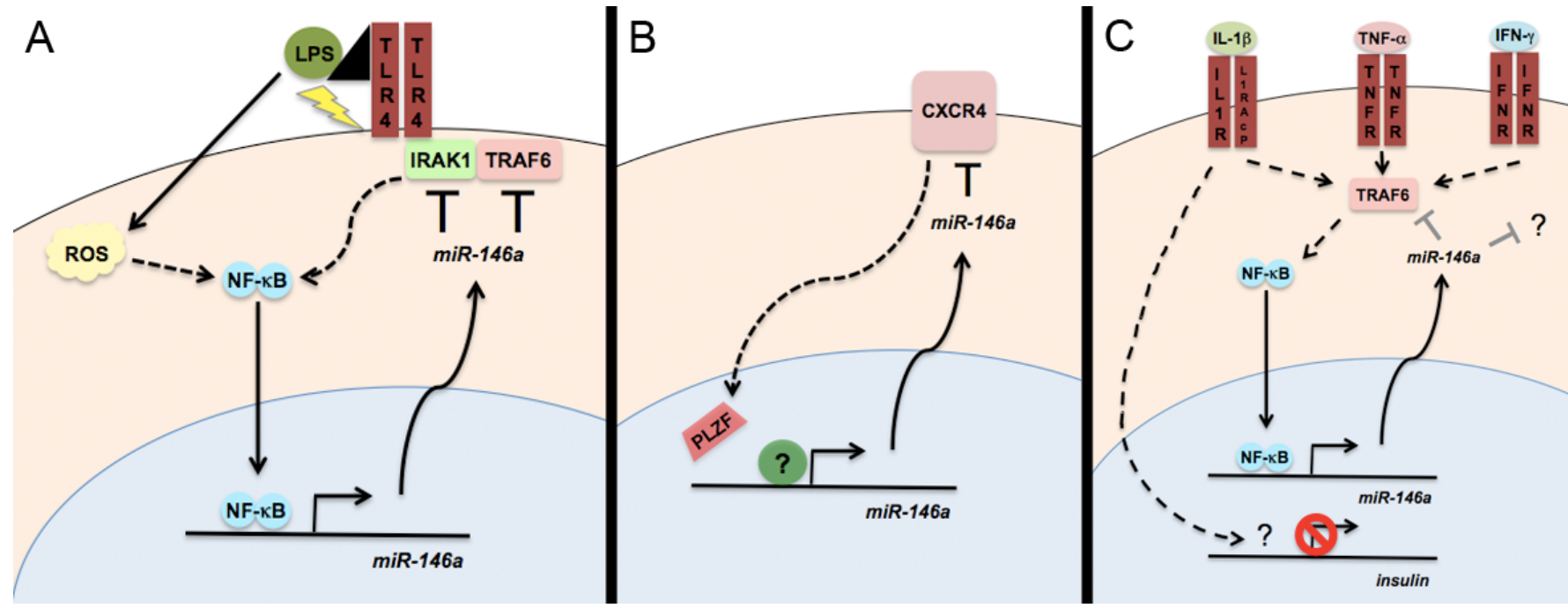

Figure 1: Activities of miR-146a in innate immunity, cell differentiation, and energy metabolism. (A) During an innate immune response, LPS activation of Toll-like receptor 4 (TLR4) recruits IRAK1 and TRAF6, which indirectly activate NF-KB. Upon entering the nucleus, NF-KB binds to and activates the transcription of miR-146a. Irak1 and Traf6 mRNA are then targeted by miR-146a for degradation. NF-KB may also be indirectly activated through reactive oxygen species (ROS). (B) In the cell differentiation events of megakaryopoiesis, transcription factor PLZF binds to and represses the miR-146a promoter, allowing for the translation of receptor CXCR4. When normal differentiation does not occur, unknown transcription factor(s) activate miR-146a, leading to the targeting and degradation of CXCr4 mRNA. PLZF is displaced by an unknown mechanism when miR-146a is upregulated in these cells. (C) When insulin-secreting cells are exposed to IL-1 $\beta$, TNF- $\alpha$ IFN- $\gamma$ receptormediated recruitment of TRAF6 leads to the indirect activation of NF-KB and upregulation of miR-146a. IL-1 $\beta$ activity also results in the downregulation of the insulin promoter. Not all targets of miR-146a are known in these cells. Solid arrow denotes direct path; dashed arrow represents indirect pathway.

such as glucose metabolism, differentiation of hematopoietic and spermatogenic cells, inflammation and immune response activity. Ongoing studies are examining its role with respect to cancer and other diseases. Characterization of additional miR-146a target genes proceeds continually, and further insight into the regulation of $m i R$ $146 a$ activity should provide useful information to the field.

Future directions of $m i R-146 a$ and $m i R-146 b$ research include a greater interrogation of their promoter regions. Specifically, it will be important to know whether PLZF binds to and upregulates miR-146a in undifferentiated spermatogonia. Likewise, the potential interaction between STAT1 and miR-146b should be tested using multiple epithelial cell lines. Additional analysis of CpG methylation levels and histone modifications in the miR-146a promoter should reveal how this microRNA is regulated epigenetically. Additional targets of $m i R-146 a$ and $m i R-146 b$ should also be identified and validated during development, cell differentiation, metabolism, and tumorigenesis. Such analysis will provide greater insight into the biological roles and significance of $m i R-146 a$ and its family member in health and disease.

\section{References}

1. Taganov KD, Boldin MP, Chang KJ, Baltimore D (2006) NF-kappaB-dependent induction of microRNA miR-146, an inhibitor targeted to signaling proteins of innate immune responses. Proc Natl Acad Sci U S A 103: 12481-12486.

2. Labbaye C, Spinello I, Quaranta MT, Pelosi E, Pasquini L, et al. (2008) A threestep pathway comprising PLZF/miR-146a/CXCR4 controls megakaryopoiesis. Nat Cell Biol 10: 788-801.

3. Huszar JM, Payne CJ (2013) MicroRNA 146 (Mir146) modulates spermatogonial differentiation by retinoic acid in mice. Biol Reprod 88: 15

4. Starczynowski DT, Kuchenbauer F, Wegrzyn J, Rouhi A, Petriv O, et al. (2011) MicroRNA-146a disrupts hematopoietic differentiation and survival. Exp Hematol 39: 167-178.

5. Ghani S, Riemke P, Schonheit J, Lenze D, Stumm J, et al. (2011) Macrophage development from HSCs requires PU.1-coordinated microRNA expression. Blood 118: 2275-2284
6. Roggli E, Britan A, Gattesco S, Lin-Marq N, Abderrahmani A, et al. (2010) Involvement of microRNAs in the cytotoxic effects exerted by proinflammatory cytokines on pancreatic beta-cells. Diabetes 59: 978-986.

7. Chen W, Zhang X, Birsoy K, Roeder RG (2010) A muscle-specific knockout implicates nuclear receptor coactivator MED1 in the regulation of glucose and energy metabolism. Proc Natl Acad Sci U S A 107: 10196-10201.

8. Perry MM, Williams AE, Tsitsiou E, Larner-Svensson HM, Lindsay MA (2009) Divergent intracellular pathways regulate interleukin-1beta-induced miR-146a and miR-146b expression and chemokine release in human alveolar epithelia cells. FEBS Lett 583: 3349-3355.

9. Kutty RK, Nagineni CN, Samuel W, Vijayasarathy C, Jaworski C, et al. (2013) Differential regulation of microRNA-146a and microRNA-146b-5p in human retinal pigment epithelial cells by interleukin-1beta, tumor necrosis factor-alpha and interferon-gamma. Mol Vis 19: 737-750.

10. Motsch N, Pfuhl T, Mrazek J, Barth S, Grasser FA (2007) Epstein-Barr virusencoded latent membrane protein 1 (LMP1) induces the expression of the cellular microRNA miR-146a. RNA Biol 4: 131-137.

11. Szenthe K, Koroknai A, Banati F, Bathori Z, Lozsa R, et al. (2013) The 5 regulatory sequences of active miR-146a promoters are hypomethylated and associated with euchromatic histone modification marks in B lymphoid cells. Biochem Biophys Res Commun 433: 489-495

12. Hulsmans M, Van Dooren E, Mathieu C, Holvoet $P$ (2012) Decrease of miR $146 b-5 p$ in monocytes during obesity is associated with loss of the antiinflammatory but not insulin signaling action of adiponectin. PLoS One 7 : e32794.

13. Liao Y, Zhang M, Lonnerdal B (2013) Growth factor TGF-beta induces intestinal epithelial cell (IEC-6) differentiation: miR-146b as a regulatory component in the negative feedback loop. Genes Nutr 8: 69-78.

14. Nakao A, Afrakhte M, Moren A, Nakayama T, Christian JL, et al. (1997) Identification of Smad7, a TGFbeta-inducible antagonist of TGF-beta signalling. Nature 389: 631-635.

15. Hurst DR, Edmonds MD, Scott GK, Benz CC, Vaidya KS, et al. (2009) Breast cancer metastasis suppressor 1 up-regulates miR-146, which suppresses breast cancer metastasis. Cancer Res 69: 1279-1283.

16. Xia H, Qi Y, Ng SS, Chen X, Li D, et al. (2009) microRNA-146b inhibits glioma cell migration and invasion by targeting MMPs. Brain Res 1269: 158-165. 
Citation: Huszar JM, Payne CJ (2013) miR-146a Influences Energy Metabolism, Cell Differentiation and Innate Immunity. Metabolomics 3: 119. doi:10.4172/2153-0769.1000119

Page 4 of 4

17. Chen YT, Kitabayashi N, Zhou XK, Fahey TJ, 3rd, Scognamiglio T (2008) MicroRNA analysis as a potential diagnostic tool for papillary thyroid carcinoma. Mod Pathol 21: 1139-1146.

18. Fulci V, Colombo T, Chiaretti S, Messina M, Citarella F, et al. (2009) Characterization of $B$ - and $T$-lineage acute lymphoblastic leukemia by integrated analysis of MicroRNA and mRNA expression profiles. Genes Chromosomes Cancer 48: 1069-1082.

19. Melkamu T, Zhang X, Tan J, Zeng Y, Kassie F (2010) Alteration of microRNA expression in vinyl carbamate-induced mouse lung tumors and modulation by the chemopreventive agent indole-3-carbinol. Carcinogenesis 31: 252-258.

20. Nahid MA, Pauley KM, Satoh M, Chan EK (2009) miR-146a is critical for endotoxin-induced tolerance: IMPLICATION IN INNATE IMMUNITY. J Bio Chem 284: 34590-34599.
21. Rusca N, Monticelli S (2011) MiR-146a in Immunity and Disease. Mol Biol Int 2011: 437301

22. Cheng HS, Sivachandran N, Lau A, Boudreau E, Zhao JL, et al. (2013) MicroRNA-146 represses endothelial activation by inhibiting pro-inflammatory pathways. EMBO Mol Med 5: 1017-1034.

23. O'Connell RM, Taganov KD, Boldin MP, Cheng G, Baltimore D (2007) MicroRNA-155 is induced during the macrophage inflammatory response. Proc Natl Acad Sci U S A 104: 1604-1609.

24. Tili E, Michaille JJ, Cimino A, Costinean S, Dumitru CD, et al. (2007) Modulation of miR-155 and miR-125b levels following lipopolysaccharide/TNF-alpha stimulation and their possible roles in regulating the response to endotoxin shock. J Immunol 179: 5082-5089.

25. Nakasa T, Miyaki S, Okubo A, Hashimoto M, Nishida K, et al. (2008) Expression of microRNA-146 in rheumatoid arthritis synovial tissue. Arthritis Rheum 58: 1284-1292.
This article was originally published in a special issue, Drug Repurposing: A New Frontier in Therapeutics handled by Editor(s). Dr. Sivanesan Dakshanamurthy, Georgetown University Medical Center, USA 